\title{
The Introduction of Fundamental nursing MOOCs and the Common Questions and Solving Method in the Process of Video Shooting
}

\author{
Yan $\mathrm{Li}^{1, \mathrm{a}}$ \\ ${ }^{1}$ College of Nursing, Hubei University of Medicine, Shiyan, Hubei province, China \\ aLainy24@126.com
}

Keywords: Fundamental Nursing; MOOCs; Video Production.

\begin{abstract}
Fundamental nursing MOOCs is the first planning courses of China Medicine Education MOOCs League. The course video, about 32 hours, with knowledge of the smallest unit, is designed by taking student as a center. In order to make the teaching content more vivid, concrete and attractive, and let learners are more likely to understand and grasp of the teaching content, teachers should show the teaching content by using a variety of means. The course is suitable for beginners and also be applied to nursing experience. There are some common questions in the process of theoretical video shooting included eyes without camera, rapid speech, slip of tongue, serious facial expressions, stiff body and other problems. These problems, detail mistakes, angle matters, mistake cutdowns, lighting problems and other problems, often exist in the process of operation video shooting. To solve these problems needs teachers try to relax and to adapt to the natural lens performance, and also need meticulously prepared by highly responsible teachers team with fully communication with filming personnel. The purpose of this article is reference for educators in production for other MOOCs courses.
\end{abstract}

\section{Introduction}

Online learning in nursing education is expanding rapidly and will elevate the education level of nurses[1]. Massive Open Online Courses (MOOCs) are designed to offer free and access to anyone who interested in studying around the world. MOOCs seem to be trending as the word and has reached a tipping point[2]. More universities are participating in MOOCs, which is no limit on the students number, studying time and place, and also a new development on the distance education field and on the concept of open education[4]. MOOCs has obvious advantages in the teaching content, teaching methods and teaching effect[5]. A growing number of students are drawn in studying by the interactivity, interest and Impromptu characteristics of MOOCs. MOOCs were widely considered as one of the most prominent educational innovations[6] and will play an important role in the future education[4].

China medicine education MOOCs league launched by more than 40 China medical colleges united by People's Medical Publishing House, which marks the beginning of a new MOOCs era in China medical education. The network platform of China medicine education MOOCs league, won the special fund of culture industry development of Ministry of Finance of People's Republic of China for 2014, is one of a project of News press and reform development programs from State Administration of Press, Publication, Radio, Film and Television of The People's Republic of China. This platform is the first to be used by medicine universities in China.

The first planning courses in the platform have been put into used in March 2016. The aim of this paper was to provide references for other educators who offer MOOCs in future, ccommon problems and countermeasures in the process of production of Fundamental Nursing MOOCs are reported below

\section{Introduction of fundamental nursing MOOCs}

Developing and launching MOOCs programs requires teachers to rethink traditional teaching methodologies and reframe content[1]. Fundamental nursing MOOCs contains as follows: course 
description, syllabus, scale standard, certification requirement, teaching video, expansion reading material. The contents of fundamental nursing MOOCs integrated training objectives of nursing profession, syllabus, nurse qualification examination requirements with textbook. The course video, about 32 hours long, consisted of 18 chapters and 235 smallest knowledge points . The course materials at https://pmphmooc.com/web/schooll/10425 are freely available to anyone.

A video describes a knowledge point. The purpose of making the content more vivid, specific, visual, attractive, and easier to understand and master the content for learners, a variety of teaching methods included beautiful pictures, question guiding, classic documentation, scene reconstruction and flash animation utilized in the video. Operation video have been manufactured for the more detailed and direct display of the processing in order to fully reflect the normalization and continuity of procedure. It is appear in the important and difficult points of operation procedure in operation video by the methods of double footage, appropriate pause and other emphatic way. Learning confusion generated in the MOOCs learning process can get timely answer with frequent exchange and interaction between teachers and learners through network platform. Network learning evaluation strategy, such as quiz and examination on the Internet, can internalize learning content for learners' knowledge structure by taking the studying content into practice immediately, can help learners keep the internal learning motivation and enable learners to achieve the objective of the course.

The course is suitable for beginners and also be applied to nursing experience. A wide variety of content representation of Well-designed video content and prelection affectionately by teachers brought completely different, fresh, interesting and attractive learning experience with MOOCs learners.

\section{Video producing of MOOCs}

Preperation before photography. The scene of teaching includes a variety of forms, such as location shooting, virtual scene shooting, synchronous of teacher and PPT slide, full ScreenCAP , scene demonstration mode, chat show, etc. Choose appropriate scenario to shoot according to the teaching contents and the existing teaching facilities or sites. Our video chose the following way, location shooting and virtual scene shooting. Scene and relevant goods must be ready before the shooting. Students are the principal of learning, but teachers are play leading role when shooting the MOOCs video. Body language, figure and appearance are very importance, so teachers need to choose appropriate dress and minimal chemical makeup.

Shooting process. After the preparation of the cameras, the angle of flim and light sources, shooting will be started. In order to guarantee the quality of the flim, first shoot the content of 2-3 minutes and put it on the computer to inspect the sharpness of images, the light of video and teachers' overall performance are well, and then begin the formal photograph. In the help of notice board, teachers teach the content according the script. But teachers should keep looking directly into the camera, avoid a slip of the tongue and act natural. A lot of pictures used in the video. If there are conditions to shoot on location, take pictures from different angles after adjusting the light by the filming crews, and then choose the best pictures to use. If none of conditions to shoot on location, consistent with the teaching content and clear pictures can be obtained in the Internet. Also some video clips used in the film, which is the charm of the videos that make knowledge more visual, intuitive, vivid and deepen the impression and attract the attention of students. Teachers taught the filming crews what kind of pictures that needed, and what is the focus of the show, and showed the contents to the filming crews before the video clips shooting.

Post production. Teachers put forward modification opinion about the video editing, video subtitles, inserted images and video clips, background music which completed by the film company. There is needed three or four times modification, with the emphasis on whether the choice of images and video clips are correct and in the right position, whether the video subtitles are complying with the keystone and difficulty of the teaching. If you need animation, there is also need to communicate with production personnel about the contents of the animation, and then modify repeatedly to ensure the animation's effect reached the standard of teachers' expectations and requirements. Precise 
post-production is icing on the cake. In order to guarantee the unified effect of whole MOOCs video, the titles, trailer and captions of video should be consistent. Video production has no fixed pattern, even if the same course, different points of the video display forms are completely different. On the basis of fully display the teaching content, MOOCs learners should be given a wonderful learning experience by increasing the interest, novelty and uniqueness of video design.

\section{Common problems and countermeasures in the process of production of fundamental nursing MOOCs}

Eyes Without Cmera. Prelection affectionately by the teacher's memory with look directly into the camera bring the feeling of face-to face communication to learners. It is often difficult to very accurate remember all the teaching content for teacher, so the idiot board is needed. Then the effect of video is affected when the teacher's eye left lens to see the idiot board. The solution is to adjust the distance between the camera and idiot board. Usually put the idiot board next to the camera directly that can reduce the size of eye shake of teacher by the smallest distance between the camera and idiot board, which as if camera bores straight into the teacher's souls all the time even when the teacher see the idiot board. Due to the small camera screen, there is difficult to find when the teacher appeared the change of the eye. For the best display effect of video and discovering the problem of eye, it was significant that make a few minutes film before formal shooting when the machine and teacher preparation and then put the film on the computer to watch carefully. If there are some flaw in the teacher's eye, It need to adjust the location of camera and idiot board until when teachers see the idiot board, also like in the camera. In parallel, need to be aware things are that readjust the location of camera and idiot board in accordance with the different shooting angle and teacher's height.

Rapid Speech. Owing to some teachers speak too fast on traditional classroom, teachers generally don't need to think about by reading the word form the idiot board when shooting the MOOCs video and be nervous from the shooting, all of these lead to the teacher's speed faster and faster. The solution is often remind teachers slow down. For example, every once in a while other personnel raise the paper that writing "slow" to remind the teacher that slow down the speed.

Slip of Tongue. A slip of tongue often appear on traditional classroom and also on the process of MOOCs video shooting. No one can assure that not appear errors which be difficult to find in a timely manner even reading the word form the idiot board. The method to solve the problem of this kind of is taken again. Staff who responsible for the idiot board watch the word seriously and stop shooting immediately once a slip of tongue appear. Then reshoot from the wrong place to replace the wrong.

Serious Facial Expressions. Teachers are always no facial expression and very serious taught in front of the cameras. Even if some teachers can guarantee with smile in the beginning of shooting, they slowly became serious in the process of teaching. On the one hand,the method to solve the problem is to give students a kind of feeling that teacher is amiable, so that teachers need time to adapt to the lens and practice how to teach with smile. On the other hand, shooting or other auxiliary personnel remind teacher to keep smile at set intervals.

Stiff Body. Teachers unavoidably feel nervous and often at a loss when shooting, which lead to that teacher standing in front of the camera read the script according to flash board, thus the effect of video would be bad. Learning how to relax yourself when shooting is the best way to solve this problem. Teachers can seek advice from experienced staff about how to act natural and relax in front of the camera. Just like giving lectures at ordinary times, the teacher's proper physical activities cooperated with the teaching content in foot, head, hands, elbows and hands as long as the foot don't walk around will show more natural. But movement range can't be too big and the gestures action can't too fast. If too much movement range can lead to part of the body the lens. If action is too fast, then appeared images may be vague. In filming, teachers need to slowly to adapt and use these skills.

Other Problems. There will be many other problems when filming, such as teacher's makeup, inappropriate pauses and kept swallowing, etc. Every problem has corresponding prevention or solution method. In front of the camera, every teacher wants a perfect show, so the makeup and clothing is very important. Under the high definition video, even if a few messy hair will affect the teacher's appearance, so the professional makeup artist is very necessary. The teacher's dress should 
very exquisite, such as daily beautiful clothes or nurse uniform are as well. If you choose the daily clothing, you'd best 1 days in advance take the clothing to the shooting area and try out for a few minutes, take a look at the clothes on the film, which can ensure the smooth film shooting that day. If teacher need to swallow saliva in the process of teaching, teacher could do a little pause and continue to teach after to swallow saliva. In post-production, in order to ensure the integrity of the video, production staff will cut off the swallow saliva fragments. Talking while swallowing is to be avoided, because it is hard to deal with the swallowing in post-production. Once inappropriate pause or other errors appear in the process of shooting, teacher could still do a little pause and then teach again from the content of the problems before.

\section{Conclusions}

It is agreement that faculty are key to the MOOCs[7], as MOOCs echo across higher education, college teachers need to keep pace with The Times and to participate in the construction of MOOCs. Creating a MOOCs is a challenge for educators and MOOCs will lead teachers to become more excited about finding new methods to help MOOCs students learn.

Hope the above introduction can help teachers avoid similar problems in the future MOOCs video shooting. The implementation and application also includes discussion, interaction, homework, tests, all of these can be realized through the network platform. Welcome the masses of teachers and learners to the MOOCs network platform (http://www.pmphmooc.com/) of People's Medical Publishing House for studying the course of Fundamental Nursing MOOCs, and provide your guidance and improvements for us.

\section{Acknowledgement}

Fund project: This paper is supported by the Research Fund Program of 2014 provincial teaching research in colleges and universities of Hubei Province projects, Project number:2014334; The teaching research project of Hubei University of Medicine,Project number:2014012.

\section{References}

[1] Schnetter, V.A. Lacy, D. Jones, M.M. et al. Course development for web-based nursing education programs[J]. Nurse Educ Pract, 2014,14(6):635-640

[2] Skiba, D.J. On the Horizon: The Year of the MOOCs[J]. Educ. Perspect, 2013,34(2):136-137

[3] Hao Dan. The Literature Analysis of the status of domestic MOOC[J]. Distance Education in China, 2013,11:42-50 (In Chinese)

[4] Xu B. Yang D. Motivation Classification and Grade Prediction for MOOCs Learners[J]. Comput Intell. Neurosci,2016,1:1-7

[5] Li Xiaodong. Challenges of MOOC to University Teachers' Quqlifications and Countermeasures[J]. Journal of Nanjing university of Science and Technology, 27(2), 2014,27 (2) :89-92 (In Chinese)

[6] Ye Yanming. MOOCs: A Fulcrum to Lever the New Reform of the Library[EB/OL]. Journal of the National Library of China, 2014,2:3-9 (In Chinese)

[7] Skiba, D.J. MOOCs and the Future of Nursing[J]. Nurs. Educ. Perspect, 2013,34(3):202-204. 